Editorial

\title{
Recent Developments in Mechanical Engineering
}

\section{Filippo Berto}

Department of Industrial and Mechanical Engineering, Norwegian University of Science and Technology, 7491 Trondheim, Norway; filippo.berto@ntnu.no

Received: 9 May 2018; Accepted: 9 May 2018; Published: 12 May 2018

Welcome to the section Mechanical Engineering in Applied Sciences. Together with the editing team, I am very happy to promote this strategic section of the journal. In the past decade, mechanical engineering has experienced substantial improvements with a change of focus in terms of scale, span, and applications. Nano and micromechanics have been developed. In addition, new requirements in terms of design efficiency have become more and more important, pushing to relevant improvements in terms of new methods and advanced approaches.

To face these new challenges, an update of existing design tools is a matter of urgency. This section publishes papers on the latest advances, as well as review articles, on various aspects of mechanical engineering. Topics will include mechanics and mechanical properties of materials used in mechanics, principle, design, material and instrumentation for mechanics, control theory and control engineering, problems relevant to mechanics including vibration and efficiency, etc. Special Issues will focus on single topic areas, for example, theoretical research, technology development, and practical implications impacting on mechanical design. This section will merge together emerging technologies and new applications with traditional solid topics related to mechanical engineering. We hope that the section will provide a broad scope to researchers and engineers in this new interdisciplinary field. The journal has a strict peer-review policy but still it aims to have a minimal delay from submission to publication. We would like to take this opportunity to thank all the authors, reviewers, and Editorial Board members for their contributions and cooperation. I would also like to thank the Editorial Office for their support. Together, we look forward to receiving your submissions, suggestions, and services. Thank you all in advance.

(C) 2018 by the author. Licensee MDPI, Basel, Switzerland. This article is an open access article distributed under the terms and conditions of the Creative Commons Attribution (CC BY) license (http:/ / creativecommons.org/licenses/by/4.0/). 